\title{
GESTACIÓN POR SUSTITUCIÓN INTERNACIONAL E INTERÉS SUPERIOR DEL MENOR: DOCTRINA DEL TEDH Y RESPUESTA DE LAS AUTORIDADES ESPAÑOLAS
}

LAURA HERNÁNDEZ LLINÁS 


\section{SUMARIO}

I. Planteamiento del tema y objetivos del trabajo. II. Respeto a la vida privada del menor cuando existe un vínculo genético con el padre intencional: los casos Mennesson y Labassée C/Francia y el Dictamen de 10 de abril de 2019 (Demanda n P162018-001). III. Desprotección del menor ante la ausencia de vínculo genético con los padres intencionales: el caso Paradiso Campanelli C/Italia. IV. Valoración de la jurisprudencia del TEDH: obligaciones de los Estados parte e interrogantes pendientes de respuesta. V. La respuesta de las autoridades españolas ante la gestación subrogada internacional a la luz de la doctrina del TEDH. VI. A modo de conclusión. 


\title{
GESTACIÓN POR SUSTITUCIÓN INTERNACIONAL E INTERÉS SUPERIOR DEL MENOR: DOCTRINA DEL TEDH Y RESPUESTA DE LAS AUTORIDADES ESPAÑOLAS.
}

\author{
LAURA HERNÁNDEZ LLINÁS ${ }^{1}$ \\ Universidad de Salamanca
}

\section{PLANTEAMIENTO DEL TEMA Y OBJETIVOS DEL TRABAJO}

El presente trabajo pretende abordar algunos aspectos problemáticos de la situación en la que se encuentran los menores nacidos en virtud de acuerdos de gestación subrogada internacional. En concreto, centraremos nuestra atención en las dificultades que existen para determinar la filiación de estos niños y niñas en los Estados de residencia de sus padres intencionales. A tal efecto, hemos de partir de una definición de la gestación subrogada o por sustitución: aquella práctica en la que una mujer se compromete a gestar y dar a luz un bebé concebido a través de técnicas de reproducción asistida, renunciando a los derechos que le corresponderían como madre en favor de la contraparte, los padres comitentes o padres intencionales ${ }^{2}$. En aquellos países donde esta figura es legal, la filiación del nacido corresponde a estos últimos, que pueden ser tanto una pareja, heterosexual u homosexual, como una mujer o un hombre que hayan decidido tener un hijo en solitario. El contrato puede ser oneroso - gestación comercial - o gratuito — gestación solidaria - la mujer gestante puede aportar su óvulo — gestación por sustitución tradicional — o no — gestación por sustitución gestacional-, y

1 Investigadora en Formación (FPU). Área de Derecho Constitucional. Departamento de Derecho Público Facultad de Derecho. Campus Miguel de Unamuno. Universidad de Salamanca. 37007 SALAMANCA. Email: laurahllinas@usal.es

2 Para una definición jurisprudencial: consiste en un contrato, oneroso o gratuito, a través del cual una mujer consiente en llevar a cabo la gestación, mediante técnicas de reproducción asistida, aportando o no también su óvulo, con el compromiso de entregar el nacido a los comitentes, que pueden ser una persona o una pareja, casada entre sí o no, que a su vez pueden aportar o no sus gametos». Sentencia n. ${ }^{\circ} 826$ de la Sección 10. ${ }^{a}$ de la Audiencia Provincial de Valencia, de 23 de noviembre de 20118. Id. Cendoj: 46250370102011100707.

(C) UNED. Revista de Derecho Politico 
para la fecundación pueden utilizarse tanto gametos de los padres intencionales como de donantes anónimos 3 .

La gestación subrogada despierta una gran polémica en la sociedad actual, generando intensos debates desde un punto de vista ético y jurídico. Para sus detractores, constituye una mercantilización de la gestación y la maternidad moralmente inaceptable, que objetualiza a los menores y las mujeres gestantes, y aprovecha las dificultades económicas de estas últimas para comerciar con su fertilidad. Para sus defensores, en cambio, la gestación por sustitución no es más que una aplicación de las nuevas técnicas de reproducción asistida al servicio de un nuevo modelo de familia, perfectamente asumible en una sociedad abierta y tolerante, que no imponga prejuicios de corte moral sobre decisiones concernientes a un asunto privado. Estas fuertes divergencias en la consideración del fenómeno de la gestación por sustitución se traducen en diferencias igualmente notables en lo que se refiere a su regulación jurídica. Así, existen Estados como Rusia, India, y algunos Estados de EE.UU. donde estos contratos son perfectamente válidos, tanto si media precio como si no, Estados donde se admiten solo si la gestación es altruista, como Canadá, Reino Unido, Grecia, Holanda, Bélgica o Dinamarca, y Estados como España, Francia, Austria, Italia, Alemania, o Hungría, donde cualquier tipo de gestación por sustitución es una práctica prohibida por el ordenamiento y, en ocasiones, sancionable en vía administrativa e incluso penal ${ }^{4}$. A su vez, allí donde son considerados legales encontramos importantes diferencias en la mayor o menor flexibilidad de los requisitos y condiciones que deben cumplirse en la celebración de estos contratos.

Las diferencias en el tratamiento legislativo de la gestación subrogada dan lugar a una modalidad de turismo internacional reproductivo o cuidados reproductivos transfronterizos ${ }^{5}$ : desplazamientos de personas residentes en países donde la gestación subrogada está prohibida o no tiene cobertura legal alguna, a países en los que este tipo de contratos sí están permitidos. Los padres intencionales se trasladan a destinos como California o Rusia, llegan a un acuerdo con una madre gestante - generalmente a través de agencias especializadas en este tipo de contratos-, y regresan a su país de residencia una vez concluido el embarazo, trayendo consigo a un menor que, en el país de nacimiento, quedará documentado como su hijo a todos los efectos. Precisar

3 Para una exposición más detallada sobre la tipología de contratos de gestación subrogada: LAMM, E. (2013) Gestación por sustitución: ni maternidad subrogada ni alquiler de vientres. Publicacions i Edicions de la Universitat de Barcelona. Barcelona. Pp. 22 - 27.

${ }^{4}$ Para una revisión del tratamiento de la gestación subrogada en el Derecho comparado: LAMM, E. Ibidem. pp. 71-185, y MONÉGER, F. (2011) Gestation pour autrui: surrogate motherhood. Académie Internationale de Droit Comparé. XVIII Congrès. Société de législation comparée. Paris.

5 Ambos términos provienen de expresiones inglesas, fertility tourism y cross-border reproductiva care. respectivamente. Generalmente, los autores que proponen el uso del segundo entienden que el primero tiene una connotación negativa. Ello se defiende en: SHENFIELD, F., DE MOUZON, J., PENNINGS, G., FERRARETTI, A. P., NYBOE ANDERSEN, A., DE WERT, G., ... \& ESHRE "Taskforce on Cross Border Reproductive Care". (2010). "Cross border reproductive care in six European countries". Human Reproduction, 25, 6, pp. 1361-1368. 
la filiación de estos menores en el lugar de destino, donde la gestación por subrogación está prohibida o no regulada, plantea problemas jurídicos de extraordinaria complejidad ${ }^{6}$. Las respuestas de los ordenamientos internos y los tribunales nacionales a esta situación, en ocasiones, pueden resultar contrarias a los derechos de estos niños y niñas, quedando en riesgo el respeto a su vida privada y familiar.

Esta situación de potencial riesgo para los intereses de los menores ha motivado diferentes pronunciamientos del Tribunal Europeo de Derechos Humanos (en adelante, TEDH). Este, si bien considera que la eventual legalización de la gestación por sustitución es una cuestión que corresponde decidir libremente a los Estados, ha exigido que su negativa a admitir la validez de estos contratos en el Derecho interno no se traduzca en la desprotección de los menores implicados en casos de gestación subrogada internacional. Con apoyo en el principio del interés superior del menor, ha elaborado una jurisprudencia especialmente garantista con los derechos de los niños en aquellos casos en que existe un vínculo genético entre ellos y alguno de los padres comitentes. Como se explicará en los apartados siguientes, su doctrina pone remedio a algunos de los problemas más frecuentemente padecidos por estos menores, pero no puede decirse que constituya una solución perfecta ni definitiva para todos los casos que pueden darse en la práctica. Son varios los expertos que han puesto de manifiesto las carencias que presenta la protección de los menores, y también la Conferencia de la Haya de Derecho Internacional Privado ha denunciado la urgencia de corregir la desprotección a la que están expuestos los menores, así como la necesidad de acabar con la inseguridad jurídica que afecta a los derechos de todas las partes implicadas en estos casos - en especial a los de las mujeres gestantes, y a los de los propios menores - En ese sentido, viene proponiendo, desde hace algunos años, la adopción de un instrumento internacional vinculante sobre reconocimiento de sentencias extranjeras en materia de filiación, y un protocolo vinculante autónomo sobre reconocimiento de decisiones judiciales extranjeras sobre filiación derivada de acuerdos de gestación subrogada internacional ${ }^{7}$. Sin embargo, dadas las reticencias que aún despierta la facilitación del establecimiento del vínculo de filiación entre los menores nacidos en el extranjero y sus padres intencionales, en la medida en que, para muchos, ello conduce a la aceptación por el ordenamiento interno de los efectos de un acuerdo realizado en fraude de ley, no es probable que un instrumento de estas características suscite el consenso necesario entre los Estados de nuestro entorno en un futuro próximo.

${ }^{6}$ La gestación subrogada internacional puede provocar situaciones aún más gravosas para el menor en aquellos casos en que el país de nacimiento no reconoce la adquisición de la nacionalidad en virtud del criterio ius soli, como sucede en India o Ucrania. Ello puede impedir que los comitentes obtengan un pasaporte o documento de viaje para el niño, dificultando su salida de dicho país. Para un estudio de estos casos LAMM, E. (2015) Op cit. pp. 196 y ss.

7 Todos los informes del Grupo de expertos en filiación y gestación subrogada internacional de la Conferencia de la Haya están disponibles en el siguiente enlace: https://www.hcch.net/es/projects/legislative-projects/parentage-surrogacy (consultado el 23/10/2019).

(C) UNED. Revista de Derecho Político

N. ${ }^{\circ}$ 107, enero-abril 2020, págs 181-210 
Así las cosas, la determinación de la filiación de estos menores en los países de residencia de sus padres intencionales, cuando el Derecho interno prohíbe o contempla como nulos los acuerdos de gestación subrogada, encuentra una serie de obstáculos frente a los cuales aún no existe una respuesta clara y compartida por la comunidad internacional. Cada Estado decide cómo afrontar esta situación, dando lugar en ocasiones, como se verá en los apartados siguientes, a una desatención del interés de los menores fruto de la voluntad de castigo a sus padres intencionales. Resulta evidente que la problemática sobre los derechos de estos menores es excesivamente amplia como para abordar su estudio con la profundidad necesaria en unas pocas páginas. En consecuencia, nuestro objetivo en este trabajo será mucho más modesto. Nos proponemos realizar un acercamiento descriptivo a la jurisprudencia más reciente el Tribunal Europeo de Derechos Humanos sobre el principio del interés superior del menor y los derechos de los menores nacidos en el marco de acuerdos internacionales de gestación subrogada, en relación con la determinación de su filiación. A tal efecto, expondremos en primer lugar la doctrina de este Tribunal sobre la exigencia de respeto al derecho a la vida privada del menor cuando existe un vínculo genético entre él y su padre intencional. Se analizarán los casos Mennesson y Labassée c. Francia, así como las novedades introducidas en la materia por el Dictamen consultivo emitido el pasado 10 de abril de 2019. A continuación, presentaremos el Caso Paradiso Campanelli c. Italia, que nos permitirá comprobar la gravedad de las situaciones de desprotección en las que pueden verse involucrados estos menores si carecen de un vínculo genético con alguno de los padres intencionales. Haremos igualmente una reflexión sobre las implicaciones que puede tener la sentencia de la Gran Sala sobre este asunto, contraponiendo los argumentos utilizados en este caso con los que sirvieron de base a los pronunciamientos anteriormente referidos, con el objetivo de poner negro sobre blanco cuáles son las obligaciones que pesan hoy en esta materia sobre los Estados parte del Convenio Europeo de Derechos Humanos, y qué interrogantes quedan aún pendientes de respuesta. Por último, dedicaremos un apartado al análisis de la respuesta que las autoridades españolas dan a estos casos, a la luz de la doctrina del TEDH, y unas últimas líneas a la síntesis de todos los aspectos abordados y a la reflexión sobre el papel que ha de jugar el interés superior del menor en la determinación de la filiación de los menores nacidos en virtud de acuerdos de gestación subrogada internacional.

En definitiva, el presente trabajo pretende ser un estudio descriptivo de la jurisprudencia del TEDH sobre el papel que ha de jugar el principio del interés superior del menor a la hora de determinar la filiación de los menores nacidos como resultado de acuerdos de gestación subrogada internacional, y nuestro objetivo no es otro que analizar y valorar dicha jurisprudencia, así como examinar la adecuación a ella de la respuesta de las autoridades españolas frente a estos casos. 


\section{RESPETO A LA VIDA PRIVADA DEL MENOR CUANDO EXISTE VÍNCULO GENÉTICO CON EL PADRE INTENCIONAL: LOS CASOS MENNESSON Y LABASSÉE C/ FRANCIA Y EL DICTAMEN DE 10 DE ABRIL DE 2019.}

Los casos Mennesson ${ }^{8}$ y Labassée 9 c. Francia, los primeros en que el TEDH se pronunció sobre los derechos de los menores nacidos por gestación subrogada, hoy pueden considerarse un punto de no retorno en lo relativo a la protección de los Derechos Humanos en el ámbito de los países signatarios del Convenio ${ }^{10}$. Tuvieron su origen en supuestos de hecho muy similares, y fueron resueltos con arreglo a un razonamiento idéntico. En ambos casos se trataba de matrimonios franceses que habían recurrido a la gestación por sustitución, en California y Minnesota respectivamente, implantando el óvulo de donantes anónimas fecundado con gametos aportados por los padres intencionales en el útero de madres gestantes, siendo estos contratos ilegales para el Derecho francés. También en ambos casos existía sentencia judicial estadounidense que determinaba la filiación de las niñas nacidas por subrogación a favor de los padres y las madres comitentes. El reconocimiento de esta filiación fue recurrido por el Ministerio Fiscal francés y, tras un largo recorrido ante los tribunales de justicia, en ambos casos la Corte de casación confirmó la imposibilidad de inscribir la filiación reconocida en las sentencias estadounidenses, por resultar ello contrario a normas imperativas de orden público ${ }^{11}$.

Estos casos presentan un elemento típico de los casos de gestación subrogada internacional: los padres intencionales regresaron a su país de residencia y las autoridades judiciales nacionales, considerando que éstos habían actuado en fraude de ley, tomaron decisiones que, en último término, a quien más perjudicaron fue a las niñas nacidas en virtud de estos contratos. A juicio del TEDH, en ambos casos resultó vulnerado el art 8 del $\mathrm{CEDH}$, no respecto al derecho a los padres intencionales y las menores al respeto de su vida familiar, ya que en ninguno de los casos se impidió la convivencia como una familia, pero sí en relación con el derecho de las menores al respeto de su vida privada. En virtud del apartado segundo del citado artículo, no cabe injerencia de la autoridad pública en el ejercicio del derecho a la vida privada, salvo que la misma esté prevista por la ley y constituya una medida necesaria en una sociedad democrática para la consecución de una serie de fines expresamente enun-

${ }^{8}$ STEDH 26 junio 2014, as. $65192 / 11$

9 STEDH 26 de junio de 2014, as. 65941/11

${ }^{10}$ Así los ha calificado ROCA TRÍAS en ROCA TRÍAS, E. (2015). "Dura Lex Sed Lex. O de cómo integrar el interés del menor y la prohibición de la maternidad subrogada", en BENAVENTE MOREDA, P. y FARNÓS AMORÓS, E. (Coords.) (2015). Treinta años de reproducción asistida en España: una mirada interdisciplinaria a un fenómeno global y actual. Boletín del Ministerio de Justicia. p. 325

${ }^{11}$ En concreto, a los arts. 16-7 CC — de contenido similar al art. 10.1 LTRHA español, que declara la nulidad de pleno derecho de estos contratos—, y 16-9 CC — que declara que las disposiciones del capítulo al que pertenece este artículo son de orden público- . 
ciados $^{12}$. De acuerdo con el TEDH (Mennesson párrafos 96 a 100; Labassée párrafos 75 a 80), en este caso la injerencia cumplía los requisitos de previsión legal y servicio a la consecución de dos de los fines legítimos contemplados por el Convenio - la protección de la salud y la protección de los derechos y libertades de los demás-, pero no podía considerarse necesaria en una sociedad democrática. En el juicio de necesidad de la medida han de tomarse en consideración todas las circunstancias del caso y los intereses concurrentes, entre los cuales - y este es uno de los elementos más importantes de este pronunciamiento- ba de primar siempre el interés superior del menor. El Tribunal reconoce, por un lado, que Francia puede tener por objetivo el desincentivar el recurso a la gestación subrogada. El margen de apreciación nacional en relación con esta cuestión es amplio, dada la ausencia de referencia expresa a ella en el $\mathrm{CEDH}$, la falta de consenso entre los Estados parte, y sus delicadas implicaciones éticas. No obstante, la amplitud de dicho margen se atenúa en lo tocante a la determinación de la filiación de los menores implicados, por estar en juego un aspecto esencial para su identidad. En este sentido, el respeto a la vida privada exige que cada uno pueda establecer su identidad como ser humano, lo cual incluye su filiación; en los casos examinados las decisiones de las autoridades francesas, al impedir no solo el reconocimiento de las actas de nacimiento expedidas en América, sino también el establecimiento de la filiación por acta de notoriedad de posesión de estado, por impugnación de la paternidad biológica o por adopción, colocaron a las menores en una situación de incertidumbre respecto a la definición de su propia identidad. Esta incertidumbre afectaba negativamente sus derechos sucesorios, y creaba una importante inseguridad respecto a su posibilidad o no de ostentar la nacionalidad francesa, a pesar de que en ambos casos el padre biológico era francés.

A la vista de todo lo expuesto, el Tribunal, en un párrafo que sintetiza a la perfección su postura respecto a los problemas generados en los casos de gestación subrogada internacional y no reconocimiento en el país de destino de la filiación de los menores, establece lo siguiente: los efectos del no reconocimiento por el Derecho francés de la filiación entre las niñas y los padres intencionales no se limitan a la situación de estos últimos (...): tienen también consecuencias para las menores, cuyo derecho a la vida privada (...) se encuentra significativamente afectado. Surge entonces una cuestión grave de compatibilidad de esta situación y el interés superior del menor, cuyo respeto debe guiar las decisiones que lo conciernen ${ }^{13}$. A continuación, añadió que debía prestarse especial atención a dos elementos concurrentes en los casos objeto de examen (Mennesson, 100; Labassée 79): la existencia de un vínculo genético con el padre intencional, y el hecho de que el reconocimiento no solo se inadmitió con ocasión del rechazo a la inscripción de nacimiento de las menores nacidas por gestación subrogada, sino que se impidió también su consagración por otras vías (reconocimiento de la paternidad, posesión de estado,

12 La seguridad nacional, la seguridad pública, el bienestar económico del país, la defensa del orden y la prevención de las infracciones penales, la protección de la salud o de la moral, o la protección de los derechos y las libertades de los demás.

13 Traducción propia (Mennesson párrafo 99; Labassée párrafo78). 
adopción). En vista de lo anterior, y atendiendo a la gravedad de la restricción del derecho a la vida privada de las menores que se desprendía de las circunstancias del caso, consideró que la actuación de las autoridades no podía enmarcarse dentro del margen de apreciación de los Estados, y que el peso que ha de otorgarse al interés del menor en la ponderación de los distintos intereses en juego hacía patente la existencia de una vulneración del CEDH.

A la luz de estas dos sentencias, por tanto, no cabe duda de que el derecho al respeto de la vida privada de un niño nacido en el extranjero a través de un acuerdo de gestación subrogada exige que la relación jurídica entre este menor y el padre comitente, cuando entre ellos exista un vínculo genético, sea reconocida por las autoridades nacionales. En estos casos, impedir el reconocimiento de la filiación por cualquier vía, en aras del respeto al orden público internacional, desborda el margen de apreciación nacional de los Estados parte. Ahora bien, ¿qué sucedería si se negase la posibilidad de inscribir el acta registral extranjera en el registro civil interno en relación con la madre intencional, con la que no existe vinculo biológico alguno? ¿sería ello contrario al art. $8 \mathrm{CEDH}$ ? ¿y si se permitiera el establecimiento de la filiación por otras vías? Por otro lado, si ninguno de los padres intencionales hubiera aportado su material genético, ¿podría considerarse lesiva del derecho a la vida privada del menor la imposibilidad de determinar su filiación a favor de éstos?

Desde que el TEDH dictara sus sentencias en 2015, la doctrina ha debatido acerca de las posibles respuestas a estas preguntas, sin llegar a conclusiones unánimemente aceptadas. Hoy algunas de ellas pueden considerarse zanjadas a raíz de su Dictamen de 10 de abril de 2019 (Demanda n. ${ }^{\circ}$ P16-2018-001), emitido en respuesta a una petición de la Corte de Casación francesa que tuvo su origen, precisamente, en un procedimiento iniciado por los demandantes del caso Mennesson. Una vez dictadas las sentencias recién comentadas, y aunque no sin algunas resistencias ${ }^{14}$, la justicia francesa ajustó su jurisprudencia permitiendo el registro de los detalles del certificado de nacimiento de los niños nacidos mediante gestación subrogada en el extranjero, en relación con el padre comitente, cuando éste sea también padre biológico del menor. No extendió, sin embargo, la posibilidad de inscribir dicho certificado respecto de la madre comitente, en caso de no haber aportado ésta su material genético. Para crear una relación jurídica con el niño, tendría la posibilidad de adoptarlo, una opción que la legislación francesa facilita para aquellas parejas que estén casadas. Disconformes con la solución que les ofrecía el ordenamiento francés, los Señores Mennesson acudieron a los tribunales internos solicitando, con base en los pronunciamientos del TEDH, que se reconociera la filiación del certificado de nacimiento extranjero también en relación con la madre comitente. La Corte de Casación, apro-

14 En los casos Foulon y Bouvet c. Francia (asuntos 9063/14 y 10410/14) el Estado francés fue, una vez más, condenado por la Sección Quinta del TEDH en 2016, con motivo de la negativa de las autoridades francesas al reconocimiento de la filiación biológica a favor de los padres biológicos de una niña (caso Foulon) y dos gemelos (caso Bouvet) nacidos en India, fruto de dos contratos de gestación subrogada.

(C) UNED. Revista de Derecho Político

N. 107 , enero-abril 2020, págs 181-210 
vechando la posibilidad que tienen los órganos jurisdiccionales de mayor rango de los Estados parte de solicitar al TEDH una opinión consultiva no vinculante sobre la interpretación o a la aplicación de los derechos definidos en el Convenio (art. 1 Protocolo 16), le trasladó dos preguntas ${ }^{15}$. En primer lugar, si el respeto al artículo 8 del Convenio exige o no que el derecho interno prevea la posibilidad de reconocer la relación entre un niño nacido en el extranjero mediante un acuerdo de gestación subrogada y la madre comitente, en aquellos casos en que no exista vínculo genético con ella, pero sí con el padre comitente. En segundo lugar, si el reconocimiento de la filiación entre la madre comitente no biológica y el menor tendría que adoptar la forma de inscripción en el registro nacional de los datos del certificado de nacimiento legalmente establecido en el extranjero obligatoriamente, o si, por el contrario, el uso de otros medios, como la adopción, daría igualmente cumplimiento a las exigencias derivadas del CEDH.

En lo que se refiere a la primera pregunta, la exigencia o no de reconocimiento de la filiación a favor de la madre comitente no biológica, el Tribunal partió, una vez más, de la amplitud del margen de apreciación con el que los Estados cuentan para regular libremente esta cuestión. Dicho margen, no obstante, se estrecha en lo tocante a aquellos aspectos de la regulación que incidan en cuestiones particularmente importantes de la identidad de una persona, como la filiación, que además afectan a aspectos esenciales de su vida privada (el entorno en el que viven y se desarrollan, y las personas responsables de satisfacer sus necesidades y garantizar su bienestar). Teniendo en cuenta el reducido margen de apreciación en estos aspectos, y las exigencias del interés superior del niño, el Tribunal opina que el derecho al respeto de la vida privada, en el sentido del artículo 8 del Convenio, de un niño nacido en el extranjero a través de un acuerdo de gestación subrogada requiere que la legislación nacional prevea la posibilidad de reconocer una relación jurídica paterno-filial con la madre comitente, designada en el certificado de nacimiento legalmente establecido en el extranjero como la "madre legítima" (párrafo 46) .

En cuanto a las vías de reconocimiento de ese vínculo entre madre e hijo, el razonamiento del Tribunal tiene como punto de partida que la identidad de una persona se cuestiona menos directamente cuando la cuestión no es el principio mismo del establecimiento o reconocimiento de su filiación, sino los medios que deben aplicarse con ese fin. Ello amplía el margen de apreciación del que disponen los Estados en lo concerniente a la elección de los medios para permitir el reconocimiento de la relación jurídica entre el menor

${ }^{15} \mathrm{La}$ formulación literal de las mismas es la que sigue: 1 . Al negarse a inscribir en el registro de nacimientos, matrimonios y defunciones los detalles del certificado de nacimiento de un niño nacido en el extranjero como resultado de un acuerdo de gestación subrogada, en la medida en que el certificado designa a la "madre comitente"1 como "madre legítima", al tiempo que acepta la inscripción en la medida en que el certificado designa al "padre comitente", que es el padre biológico del niño, ¿el Estado Parte se extralimita en su margen de discrecionalidad en virtud del artículo 8 del Convenio Europeo para la Protección de los Derechos Humanos y de las Libertades Fundamentales? A este respecto, ¿debe hacerse una distinción dependiendo de que el niño haya sido concebido utilizando los óvulos de la "madre comitente"? 2. En caso de respuesta afirmativa a cualquiera de las dos preguntas anteriores, ¿la posibilidad de que la madre comitente adopte al hijo de su cónyuge, el padre biológico, como medio para establecer la relación jurídica materno-filial, garantizaría el cumplimiento de los requisitos del artículo 8 del Convenio? 
y los progenitores comitentes. En consecuencia, y dado que el art. 8 no impone a los Estados la obligación general de reconocer ab initio una relación paterno-filial entre el niño y la madre comitente, sino que $(L)$ o que el interés superior del niño -que debe ser evaluado principalmente in concreto y no in abstracto- requiere es que el reconocimiento de esa relación, legalmente establecida en el extranjero, sea posible como máximo cuando se haya convertido en una realidad práctica (P 52), el Tribunal concluye, que las alternativas al registro, en particular la adopción por parte de la madre comitente, pueden considerarse aceptables en la medida en que el procedimiento establecido por la legislación nacional garantice que puedan aplicarse con prontitud y eficacia, de conformidad con el interés superior del niño (P 55).

En definitiva, una lectura del art. $8 \mathrm{CEDH}$ a la luz del principio del interés superior del menor impone a los Estados parte no solo el reconocimiento de la filiación del menor nacido por gestación subrogada a favor de su padre biológico, sino también a favor de la madre comitente. El respeto al Convenio, no obstante, no impone un medio determinado de reconocimiento de dicho vínculo, siendo suficiente que el medio elegido libremente por el Estado no dilate la situación de inseguridad jurídica del menor en el tiempo, y permita el reconocimiento de esa relación de manera eficaz.

\section{DESPROTECCIÓN DEL MENOR ANTE LA AUSENCIA DE VÍNCULO GENÉTICO CON LOS PADRES INTENCIONALES: EL CASO PARADISO CAMPANELLI C/ ITALIA.}

A pesar de lo que hemos visto hasta ahora, la protección de los menores involucrados en casos de gestación subrogada internacional no siempre ha jugado a favor del mantenimiento de su relación con los padres comitentes. En este sentido, resulta obligado detenernos, aunque sea de forma breve, en el asunto Paradiso y Campanelli. Este caso constituye un retrato particularmente dramático de la gravedad de los perjuicios que pueden sufrir los menores en este tipo de situaciones.

En esta ocasión, el origen del recurso presentado ante el TEDH fue un contrato oneroso de gestación por sustitución llevada a cabo en Rusia, cuyos efectos en relación con la filiación del menor querían hacerse valer en Italia, donde dicha práctica es ilegal. Sin embargo, la vulneración de sus derechos que el matrimonio italiano recurrente expuso ante el Tribunal de Estrasburgo no tenía su origen en la negativa de las autoridades nacionales a inscribir el certificado de nacimiento del menor, sino en una medida mucho más drástica: la consideración del niño en situación de abandono, al carecer de vínculo genético con ninguno de los padres intencionales y desconocerse la identidad de sus padres biológicos, y la consecuente apertura de un proceso de adopción del que fueron excluidos los padres intencionales.

El menor que protagonizó este desafortunado caso nació en Rusia, en febrero de 2011, donde permaneció dos meses bajo el cuidado de la Señora Paradiso, madre intencional, hasta que ésta lo llevó consigo a Italia en abril de ese mismo año. Los 
intentos de la Señora Paradiso y su marido, el Señor Campanelli, por inscribir el acta de nacimiento del bebé en el Registro nacional motivaron una investigación de las autoridades italianas sobre el origen del menor. Desde un primer momento, la Fiscalía, una vez tras la sospecha de que había existido un contrato de gestación subrogada, además de acusar a los padres intencionales en vía penal de alteración de la filiación, falsificación documental y contravención del procedimiento sobre adopción internacional, solicitó la declaración del menor en estado de abandono y la apertura de un proceso de adopción. En el marco del proceso concerniente a la situación del menor, se solicitó una prueba de ADN a fin de demostrar la existencia de un vínculo genético entre él y el Señor Campanelli. Aunque la intención del matrimonio había sido que este último aportara su material genético, se demostró que, por negligencia de la agencia rusa a través de la cual se puso en marcha el proceso de gestación, los gametos utilizados para fecundar el óvulo de una donante anónima que se implantó en el útero de la madre gestante no fueron del padre intencional, sino de un donante desconocido. Una vez conocido el resultado del test de ADN, la Señora Paradiso y el Señor Campanelli solicitaron que un psicólogo evaluara su relación con el menor, y su idoneidad para asumir su cuidado, con la intención de que no se separase al bebé del seno familiar en el que estaba creciendo, y de iniciar ellos mismos los trámites para su adopción. En el informe elaborado a raíz de su solicitud se recogía, efectivamente, que ya existía una relación afectiva fuerte entre el bebé y los padres intencionales, y que éstos ofrecían un entorno afectivo y económico idóneo para su desarrollo. Sin embargo, el Tribunal de menores dispuso el 20 de octubre de 2011 — tras dos meses de convivencia del bebé y la Señora Campanelli en Rusia, y seis meses más con ambos padres intencionales en Italia - la puesta del menor en manos de los servicios sociales, y su traslado a una "casa familia", en un pronunciamiento inmediatamente ejecutivo. No solo se consideró que el perjuicio provocado al menor a consecuencia de la separación no sería irreparable, dada su corta edad y la brevedad del tiempo que había trascurrido con el matrimonio, sino que se razonó que tal alejamiento respondía, en realidad, a su mejor interés, ya que la trayectoria de éstos, y en particular de la Señora Paradiso, dispuesta a todo con tal de cumplir su deseo de ser madre, ponía en duda su idoneidad para asumir el cuidado de un bebé ${ }^{16}$. A partir de entonces, y a pesar de los sucesivos

${ }^{16}$ La Sentencia del TEDH reproduce el pronunciamiento del Tribunal de menores. Este último, si bien reconoce que el menor "probablemente sufrirá un perjuicio como consecuencia de su separación de los señores Campanelli y Paradiso", entiende que, dada la brevedad del periodo que habían pasado juntos, así como su corta edad, no puede compartirse el parecer de la psicóloga según la cual la separación comportaría "consecuencias devastadoras para el menor". Consideró también que la trayectoria del matrimonio, y en particular de la Señora Paradiso, cuyo deseo de ser madre la había llevado a poner en riesgo su vida para someterse a peligrosas técnicas de reproducción asistida, sin éxito, y posteriormente a quebrantar la legislación italiana, a pesar de estar ya en posesión de una autorización para recurrir a la adopción internacional, hacía "pensar y temer que el menor fuera un instrumento para la realización de un deseo narcisista de la pareja, o liberarse de un problema individual o de pareja". Todo ello (...) "levanta una sombra importante sobre la existencia de una verdadera capacidad afectica y educativa y de un instinto de solidaridad bumana, que deben estar presentes en quienes desean integrar hijos de otras personas en su vida como si fueran propios". 
recursos interpuestos por el matrimonio italiano, el menor no volvería a estar en contacto con ellos. Permaneció cerca de quince meses en una casa de acogida hasta que, en enero de 2013, fue entregado a una familia con vistas a su adopción. Durante todo ese tiempo estuvo privado de identidad, para impedir que los padres intencionales pudieran localizarlo. Ello generó una situación de incertidumbre en las relaciones del menor con la Administración y en su acceso a los servicios públicos, ya que éste carecía de identidad a efectos de su inscripción en el censo, de su matriculación en la escuela, o del seguimiento de su cartilla de vacunación. En atención a tales perjuicios, su tutor legal solicitó en abril de 2013 que se le concediera una identidad convencional, petición que fue atendida por el Tribunal de menores, normalizándose así su situación administrativa.

El caso Paradiso Campanelli llegó a conocimiento del TEDH por medio de un recurso presentado por el matrimonio italiano en nombre propio y en nombre del menor. Plantearon al Tribunal que la decisión de alejar a este último del seno familiar en el que se estaba desarrollando había vulnerado los derechos de todos ellos al respeto de su vida privada y familiar. En una primera sentencia, dictada por la Sección Segunda del TEDH el 27 de enero de 2015, se desestimaron las pretensiones presentadas en nombre del menor, entendiendo que los padres intencionales no podían ostentar su representación. No obstante, se condenó al Estado italiano por apreciarse una vulneración del art. $8 \mathrm{CEDH}$ en relación con la vida familiar de los recurrentes. El Tribunal de Estrasburgo siempre ha mantenido que el derecho al respeto de la vida familiar no protege vínculos de iure, sino de facto, y entre éstos y el menor nacido en Rusia existía ya una vida en común merecedora de protección. A juicio de esta Sección, las decisiones de las autoridades judiciales italianas habían resultado desproporcionadas; la retirada del menor de su entorno familiar es una medida extrema, que debe adoptarse solo como último recurso, en caso de que éste corra un peligro extremo, y las circunstancias de este caso no justificaban su adopción. En consecuencia, condenó al Estado italiano al pago de 20.000 euros a los recurrentes, si bien se optó por mantener al menor en el seno de su nueva familia, por considerar que un nuevo traslado perjudicaría de nuevo su interés.

La decisión de la Segunda Sección despertó el interés de la doctrina, dentro y fuera de Italia. Se alzaron tanto voces en defensa de lo que consideraban una respuesta equilibrada y garantista por parte del Tribunal, como voces críticas con la misma ${ }^{17}$. Fue, además, objeto de recurso ante la Gran Sala por el Gobierno italiano, dando lugar

17 Como voces críticas cabe citar las de Berti di Marinis, en BERTI DI MARINIS, G. (2015) "Maternità surrogata e tutela dell'interesse superiore del minore: una critica alla luce di un recente intervento della Corte EDU”. Actualidad Jurídica Iberoamericana. 3, pp. 287-312., u Ornella Feraci en FERACI, O. (2015) “Maternità surrogata conclusa all'estero e Convenzione europea dei diritti dell'uomo: riflessioni a margine della sentenza Paradiso e Campanelli c. Italia". Cuadernos de derecho transnacional. 7, 2, pp. 420-439. A favor de la solución del TEDH de condenar al Estado Italiano, LAMM, E. (2012) "La importancia de la voluntad procreacional en la nueva categoría de filiación derivada de las técnicas de reproducción asistida”. Revista de bioética y derecho. 24, pp. 76-91.

(C) UNED. Revista de Derecho Político

N. ${ }^{\circ}$ 107, enero-abril 2020, págs 181-210 
a un cambio de parecer del Tribunal ${ }^{18}$. El examen de la Gran Sala se limitó, de nuevo, a las alegaciones presentadas en nombre propio por el matrimonio italiano. En relación al respeto de la vida familiar que la Sección consideró vulnerado, se entendió en este nuevo pronunciamiento que no había existido tal violación. El interés que los padres intencionales tenían en mantener la relación con el menor, para así poder adoptarlo — razonó esta vez el Tribunal-, debía ponderarse con el interés público, ya que dar satisfacción a su pretensión "babría resultado equivalente a legalizar una situación que estos crearon en contra de importantes normas de Derecho italiano" (P 215). Las autoridades italianas tomaron en consideración este debido respeto al interés público, sin dejar por ello de prestar atención a las concretas circunstancias del caso, ni de valorar el interés del menor. En vista de todo lo anterior, el Tribunal aceptó la razonabilidad de las decisiones de las autoridades judiciales nacionales, y entendió que su balance de los intereses en juego podía considerarse comprendido dentro del margen de apreciación del Estado italiano.

Puede resultar sorprendente que en la sentencia que resolvió de forma definitiva el asunto Paradiso Campanelli se aceptara la adecuación al CEDH de una medida tan extrema como la que adoptaron las autoridades italianas. El interés superior del menor, cuya fuerza se sobrepuso a la del orden público en los pronunciamientos dirigidos contra el Estado francés, no tuvo en este caso virtualidad suficiente como para deslegitimar las actuaciones del Estado italiano. Para dimensionar de forma adecuada las implicaciones pro futuro de esta sentencia, es necesario tener presentes las circunstancias particulares de este caso y, muy especialmente, que en el procedimiento ante el TEDH no fueron objeto de examen las posibles vulneraciones de los derechos del menor, sino exclusivamente los derechos de los padres intencionales. Probablemente, el sentido del fallo hubiera sido distinto si se hubiera considerado al matrimonio italiano legitimado para representar los intereses del menor, de tal forma que las injerencias en los derechos de este último pudieran ser valoradas a la luz del $\mathrm{CEDH}$. Al margen de las consideraciones sobre la oportunidad o no de haber realizado una interpretación más flexible de las exigencias de legitimación activa, en pro de la mayor eficacia de los derechos reconocidos en el Convenio ${ }^{19}$, lo que nos interesa des-

18 Sobre la sentencia de la Gran Sala de 24 de enero de 2017: VELA SÁNCHEZ, A. J. (2017) ¿Ha variado el TEDH su Doctrina favorable a los convenios de gestación por sustitución realizados en países que legalmente los permiten? A propósito de la Sentencia de la Gran Sala del TEDH de 24 de enero de 2017. Diario La Ley. 8953, 1.

19 Si bien es cierto que una lectura apegada a la letra de dicho Convenio avala la conclusión del Tribunal sobre la imposibilidad de considerar al menor parte del procedimiento, también lo es que existían razones suficientes para apostar por una interpretación más flexible de las exigencias de legitimación activa, en pro de la máxima eficacia de los derechos humanos. Al fin y al cabo, impedir a los comitentes la representación del menor, en la práctica, dejaba los intereses de este por completo desprotegidos: considerando que sería muy improbable que la familia adoptiva estuviera dispuesta a correr el riesgo de interponer una demanda susceptible de motivar un pronunciamiento judicial que devolviera al menor a sus padres intencionales, el Señor Paradiso y la Señora Campanelli eran las únicas personas que, presumiblemente, podían estar interesados en promover la defensa de los derechos del menor. 
tacar ahora es que fue la decisión de centrar el razonamiento exclusivamente en las injerencias en los derechos de los padres intencionales lo que condujo a aceptar la validez definitiva de una medida que, de haberse examinado desde un enfoque distinto, probablemente habría sido calificada como desproporcionada y contraria al art. $8 \mathrm{CEDH}$. Siendo así, no parece adecuado deducir de esta sentencia que el Tribunal haya cerrado la puerta al desarrollo de una jurisprudencia más comprometida con la defensa de aquellos menores nacidos por gestación subrogada que no tengan vínculo genético alguno con sus padres intencionales.

\section{VALORACIÓN DE LA JURISPRUDENCIA DEL TEDH: OBLIGACIONES DE LOS ESTADOS PARTE E INTERROGANTES PENDIENTES DE RESPUESTA.}

La figura de la gestación por sustitución plantea numerosos interrogantes de muy difícil respuesta: ¿es éticamente correcto permitir que la gestación sea objeto de comercio? ¿lo sería una gestación subrogada altruista? ¿cualquier compensación económica a la madre gestante, independientemente del resto de circunstancias, implica una explotación de la mujer? Y en caso contrario, ¿cuál sería la cuantía razonable para compensar el proceso de gestación y alumbramiento, y todos los riesgos que estos conllevan? ¿Y qué hacer en el caso de que, tras el parto, la madre gestante no quisiera renunciar a sus derechos sobre el recién nacido? ¿merecería algún tipo de protección, incluso si no aportó su material genético?

La cantidad de variantes que admite la gestación por sustitución, la diversidad de situaciones en las que pueden encontrarse tanto las gestantes como los comitentes, los numerosos intereses en juego, y los complicados dilemas morales que plantea este fenómeno nos permitirían continuar añadiendo preguntas a lo largo de varias páginas más. Todas ellas son cuestiones que, sin duda, merecen ser objeto de una reflexión pausada, y sería conveniente que existiera un debate público informado y responsable en torno a ellas, para posteriormente articular la respuesta normativa que la sociedad en su conjunto considerase oportuna. Sin embargo, y a pesar de su incuestionable relevancia para la regulación de esta figura en el Derecho interno, no es en estas cuestiones donde hay que poner el foco de atención en los casos que ahora comentamos. En este trabajo se ha tratado de visibilizar la situación de desprotección en la que pueden quedar los niños nacidos en virtud de estos contratos más allá de las fronteras de los Estados de residencia de sus padres intencionales. Sin haber sido parte de estos acuerdos, sus efectos —o la falta de reconocimiento de los mismos - tienen una enorme repercusión en sus posibilidades de desarrollo y en el disfrute de sus derechos. Cuando las autoridades nacionales están ante este tipo de situaciones, el principal interrogante al que debemos dar respuesta es el siguiente: ¿qué responde mejor al interés del menor?

(C) UNED. Revista de Derecho Politico

N.o 107 , enero-abril 2020, págs 181-210 
En los derechos e intereses de los menores es, precisamente, donde ha centrado su atención el TEDH. Como es sabido, su labor de protección de los derechos humanos es necesariamente casuística, y sus fallos están muy condicionados por las circunstancias concretas de los asuntos objeto de su conocimiento. No obstante, los diferentes pronunciamientos que ha emitido en esta materia nos permiten extraer algunas conclusiones importantes. Como se ha visto, el Tribunal distingue entre los casos estrictamente nacionales y aquellos que presentan elementos internacionales. En lo que se refiere a los primeros, reconoce plena libertad a los Estados para decidir las consecuencias que sus ordenamientos atribuirán a este tipo de contratos. En los segundos, ha determinado que de la conjunción del artículo $8 \mathrm{CEDH}$ y el principio de interés superior del menor se desprenden una serie de limitaciones a la respuesta estatal. En particular, cuando existe un vínculo genético entre el niño nacido por gestación por sustitución y alguno de los padres intencionales, la negativa estatal absoluta al reconocimiento de dicha filiación constituiría una injerencia desproporcionada en el derecho del menor al respeto de su vida privada, que incluye el respeto a su identidad. En estos casos, el Estado deberá garantizar el establecimiento de dicho vínculo por el medio que se estime oportuno, así como la posibilidad de fijar la filiación respecto del padre o madre intencional que no aportó material genético. El medio utilizado, cuya elección queda reservada al legislador nacional, deberá normalizar con prontitud y eficacia la situación del menor. A mi juicio esta doctrina, contenida en los pronunciamientos relativos al Estado francés comentados en este trabajo, ha resuelto de manera equilibrada los intereses en conflicto: ha sabido dar una protección suficiente a los menores, respetando la deferencia debida a los Estados, que mantienen todavía un amplio margen de maniobra para elegir los medios con los que reconocer el vínculo entre el menor y los padres intencionales. Considero, no obstante $-\mathrm{y}$ sobre ello volveré en seguida - que las exigencias para los Estados parte que el Tribunal deduce del artículo $8 \mathrm{CEDH}$ han de ser tomadas por éstos como un estándar mínimo de protección cuya observación es ineludible, pero no como horizonte último de la protección debida a los menores. Es deseable que los poderes públicos nacionales superen el mínimo marcado por el Tribunal de Estrasburgo y ofrezcan una mejor garantía de los derechos en juego.

La situación de los menores nacidos en el marco de un contrato de gestación por sustitución internacional se complica si éstos no comparten un vínculo genético con ninguno de los padres intencionales. En estos casos, la jurisprudencia del TEDH no nos permite extraer todavía una respuesta clara sobre los límites de la actuación estatal. Por un lado, los razonamientos de su último dictamen en favor de reconocer la filiación a favor de la madre que no aportó su óvulo podrían llevar a interpretar que la inexistencia de un vínculo genético no obsta para que el reconocimiento de un vínculo con ambos padres intencionales sea la opción que mejor responde al interés del nacido. Además, no parece razonable tomar, como criterio determinante para ofrecer una mayor o menor protección al menor, la existencia o no de un vínculo que no depende en absoluto de su voluntad, sino, en todo caso, de las decisiones de quienes 
actúan, de facto, como sus padres. Por otro lado, sin embargo, no puede desconocerse la solución que el Tribunal le dio al Caso Paradiso Campanelli, la única ocasión en la que ha conocido de un asunto en el que no existía ligamen genético alguno entre el menor y la pareja que pretendía los derechos derivados de su patria potestad. Si una medida tan drástica como el alejamiento del menor del seno familiar en el que se está desarrollando, a pesar de haber sido este entorno considerado idóneo para su crecimiento en los informes psicológicos presentados, no mereció una condena del Estado, ¿la merecería una injerencia de menor gravedad, como puede ser la negativa a reconocer un vínculo jurídico entre el niño y sus padres intencionales?

La respuesta a este último interrogante no es sencilla. Debe tenerse en cuenta que para el Tribunal el reconocimiento de la filiación hace parte de la identidad del menor $y$, en consecuencia, está protegido por el derecho a la vida privada del menor. Es este derecho, y no los derechos de los adultos que pretenden su patria potestad, el que se considera ilegítimamente restringido cuando se niega la posibilidad de establecer con claridad su filiación. Ni la eventual vulneración de este derecho, ni una posible vulneración del respeto a la vida familiar del menor pudieron examinarse en el asunto Paradiso Campanelli, en el que el Tribunal tan solo conoció de las injerencias realizadas por el Estado italiano en los derechos de la pareja comitente. Como se ha explicado, si se hubiera hecho una interpretación más flexible de las exigencias de legitimación activa, considerando al matrimonio italiano legitimado para representar los intereses del menor, es posible que el sentido del fallo hubiera sido distinto. El enfoque formalista en materia de legitimación por el que optó el Tribunal lo llevó a desaprovechar la oportunidad de sentar un precedente más garantista, y más sensible con la protección de los menores no vinculados genéticamente con ninguno de sus padres intencionales. Ahora bien, dado que la solución que dispuso para este asunto estaba muy ligada a los pormenores del caso, y en ausencia de un desarrollo posterior de esta línea jurisprudencial, no cabe deducir de ella que el Tribunal considere legítimo tratar de distinto modo a los niños nacidos por gestación subrogada en función de su genealogía, a la hora de facilitar el reconocimiento - o establecimiento ex novo — de un vínculo de filiación a favor de quienes asumen de facto su cuidado.

\section{LA RESPUESTA DE LAS AUTORIDADES ESPAÑOLAS ANTE LA GESTACIÓN SUBROGADA INTERNACIONAL A LA LUZ DE LA DOCTRINA DEL TEDH.}

Como se ha visto en el apartado anterior, aún quedan algunas dudas en relación con la protección que los Estados deben dispensar a los menores nacidos por gestación subrogada en el extranjero, cuando éstos carecen de vínculo genético alguno con los padres intencionales. Lo que sí puede inferirse con claridad de las sentencias que el TEDH ha dictado hasta ahora es que éstos tienen el deber de permitir el establecimiento de la filiación de los menores respecto del comitente con quien compartan un

(C) UNED. Revista de Derecho Politico

N. ${ }^{\circ}$ 107, enero-abril 2020, págs 181-210 
vínculo genético y, en su caso, respeto de aquel que asuma su cuidado conjuntamente con el primero ${ }^{20}$. Para dar cumplimiento a dicha obligación, los Estados tienen libertad de elección de medios. Es preciso señalar, no obstante, que no todos los medios a disposición de los Estados son susceptibles de dar un mismo grado de satisfacción a los derechos en juego. En este sentido, a mi juicio, en España no ofrecemos una solución idónea a la situación de estos menores, y ello a pesar de que nuestras autoridades están cumpliendo el estándar de protección fijado por el Tribunal de Estrasburgo.

La filiación de los niños nacidos en el extranjero ha generado una controversia doctrinal reseñable entre nosotros, aderezada con pronunciamientos contradictorios de la Dirección General de los Registros y el Notariado (DRGN) y de nuestros jueces y tribunales. No es este el momento para detenernos en la exposición detallada de la evolución de las posturas de estos actores en los últimos años, tarea a la que ha dado cumplida cuenta nuestra doctrina ${ }^{21}$; a los efectos de la valoración de la respuesta española a la luz de la doctrina del Tribunal de Estrasburgo, nos bastará con exponer de forma sucinta la situación actual. En virtud del artículo 10 de la Ley 14/2006, de 26 de mayo, sobre técnicas de reproducción humana asistida, será nulo de pleno derecho el contrato por el que se convenga la gestación, con o sin precio, a cargo de una mujer que renuncia a la filiación materna a favor del contratante o de un tercero. Siguiendo lo establecido en los apartados segundo y tercero del mismo artículo, la filiación de los hijos nacidos en estos casos será determinada por el parto (mater sempre cerca est), quedando a salvo la posible acción de reclamación de la paternidad respecto del padre biológico, conforme a las reglas generales. No existe previsión normativa específica que determine

${ }^{20}$ Es importante destacar que la posición favorable a facilitar el establecimiento del vínculo de filiación entre estos menores y los padres intencionales está lejos de suscitar un consenso amplio entre la doctrina. Son varios los autores que se han mostrado escépticos, cuando no abiertamente contrarios, a esta flexibilización de la excepción del orden público en atención al interés superior del menor. En este sentido, cabe citar los siguientes trabajos: BALAGUER CALLEJÓN, M. L. (2017). Hij@ s del mercado. La maternidad subrogada en un Estado social. Cátedra; SALAZAR BENÍTEZ, O. (2017). La gestación por sustitución desde una perspectiva jurídica: Algunas reflexiones sobre el conflicto entre deseos y derechos. Revista de Derecho Político. 99, pp. 79-120; MARRADES PUIG, A. (2017). El debate sobre la gestación subrogada en España: entre el deseo, la dignidad y los derechos. Revista Europea de Derechos Fundamentales. 30, pp. 153-177.

${ }^{21}$ Entre otras: BLANCO-MORALES LIMONES, P. (2015). "Una filiación: tres modalidades de establecimiento. La tensión entre la ley, la biología y el afecto”. Bitácora Millennium dipr: Derecho Internacional Privado. 1, 1. DURÁN AYAGO, A. (2012). "El acceso al Registro Civil de certificaciones registrales extranjeras a la luz de la Ley 20/2011: relevancia para los casos de filiación habida a través de gestación por sustitución". Anuario español de derecho internacional privado, 12, pp. 265-308. FARNÓS AMORÓS, E. (2010) "Inscripció a Espanya de la filiació derivada de l'accés a la maternitat subrogada a California". Indret: Revista para el Análisis del Derecho. 1. QUIÑONES ESCÁMEZ, A. (2009). "Doble filiación paterna de gemelos nacidos en el extranjero mediante maternidad subrogada: en torno a la RDGRN de 18 de febrero de 2009”. Indret: Revista para el Análisis del Derecho. 3. Para una revisión del tratamiento judicial de este problema, desde un enfoque más crítico con la figura de la gestación subrogada: VAQUERO PINTO, M. J. (2018) “¿Debe admitirse y regularse la gestación por sustitución?” en BARBER CÁRCAMO, R., QUICIOS MOLINA, M.S., VEREDA SERVER, R.A. (Coords.) Retos actuales de la filiación. Tecnos. pp. 229-268. 
cómo actuar en casos de llegada de un menor nacido en el extranjero en virtud de uno de estos contratos.

El Tribunal Supremo se pronunció sobre esta cuestión en el año 2014, a raíz del intento, por parte de un matrimonio formado por dos varones, de inscribir en el Registro Civil la filiación a su favor de dos menores nacidos por gestación subrogada que constaba en una certificación registral californiana. En su sentencia, razonó que para poder reconocer validez extraterritorial a una decisión extranjera no cabe exigir que ésta respete el Derecho sustantivo nacional, pero sí que ello no resulte manifiestamente incompatible con el orden público internacional español ${ }^{22}$. A renglón seguido, el Tribunal tomó en consideración una serie de elementos que lo llevaron a concluir que la inscripción de las certificaciones registrales fruto de estos contratos resultaría contraria al orden público internacional español, y añadió que la apelación al interés superior del menor no puede atenuar dicha conclusión, ya que este principio sirve para guiar la interpretación de la ley y para colmar sus lagunas, pero no para llevar a cabo una interpretación correctora que permita alcanzar una solución contraria a la letra de la ley (STS 6 febrero 2014, FD 5.6). La posibilidad de inscribir la filiación que consta en una certificación extranjera quedó, por tanto, descartada. Sin embargo, como el propio Tribunal indicó, ello no supone un obstáculo insuperable para la consecución del objetivo de establecer la filiación del menor a favor de los comitentes, ya que éstos pueden recurrir a otras vías alternativas que permiten la formalización jurídica de la integración real de los menores en su núcleo familiar, en concreto, la reclamación de la paternidad respecto del padre biológico y las figuras del acogimiento familiar y la adopción (FD 5.11).

La solución dada por nuestro Tribunal Supremo al caso apenas expuesto es compatible con la jurisprudencia del TEDH. Esta compatibilidad fue razonada por el propio Tribunal español en su auto de 2 de febrero de $2015^{23}$, emitido en respuesta a un incidente de nulidad de actuaciones por vulneración de los derechos fundamen-

22 Para un estudio esquemático de los razonamientos y consecuencias pro futuro de esta sentencia: HEREDIA CERVANTES, I. (2014). "El Tribunal Supremo y la gestación por sustitución: crónica de un desencuentro”. El notario del siglo XXI. 54. Para un análisis de mayor profundidad: CALVO CARAVACA, A., CARRASCOSA GONZÁLEZ, J. (2015) "Gestación por sustitución y derecho internacional privado. Más allá del tribunal supremo y del tribunal europeo de derechos humanos”. Cuadernos de Derecho Transnacional. 7, 2, pp. 45-113. En este trabajo se analiza con detalle la corrección del método utilizado por el TS (planteamiento del problema como una cuestión de validez extraterritorial de decisiones extranjeras, y no un conflicto de leyes aplicables), y se explican las diferencias de la postura de este Tribunal con las previamente sostenidas por la DGRN en 2009 y 2010, así como con la defendida por el Juzgado de primera Instancia núm. 15 de Valencia en su sentencia dictada el 15 septiembre de 2010, y por la Audiencia Provincial de Valencia, Sección 10a , en su sentencia de 23 noviembre de 2011, que antecedieron a la sentencia de casación.

${ }_{23}$ Para un estudio exhaustivo del auto citado, DURÁN AYAGO, A. (2015). "Una encrucijada judicial y una reforma legal por hacer: la gestación por sustitución”. Bitácora Millennium DIPr: Derecho Internacional Privado. 2, 2. La autora, si bien entiende ajustados a Derecho los razonamientos del TS, se muestra crítica con el legislador que, a su entender, está dejando "que sea la improvisación judicial la que dé respuesta a estos casos, con el consecuente riesgo de disparidad en las soluciones y la consecuente merca de seguridad

(C) UNED. Revista de Derecho Politico

N. ${ }^{\circ}$ 107, enero-abril 2020, págs 181-210 
tales contra la sentencia apenas mencionada, interpuesto por los padres intencionales a raíz de la publicación de la sentencia del TEDH en el asunto Mennesson Labassée. En aquel momento podían existir dudas sobre la adecuación del pronunciamiento español a la doctrina del TEDH, pero el Dictamen 10 de abril de 2019 ha confirmado que, tal y como interpretó nuestro TS años atrás, lo que resultaría una injerencia en los derechos de los niños desproporcionada y prohibida por el CEDH sería la negación de toda posibilidad de establecer lazos paterno-filiales entre los comitentes y los niños, especialmente de existir un vínculo genético entre ellos, pero no la negativa a la inscripción de la certificación extranjera cuando el ordenamiento prevea otras formas de establecer la filiación, salvando así los intereses de los menores. Nada puede decirse, por tanto, en contra de la corrección de la interpretación que nuestro Tribunal hizo de la doctrina del TEDH. Para algunos autores, además, es una solución perfectamente ajustada a Derecho, que pondera acertadamente el interés superior del menor con los demás intereses concurrentes. Es el caso de VELA SÁNCHEZ que, a pesar de haberse declarado en numerosas ocasiones partidario de la regulación de la gestación por sustitución ${ }^{24}$, se adelantó a esta sentencia, y un año antes de su publicación ya argumentaba que " $(E) l$ interés superior del menor, que no es absoluto ni ilimitado, no puede servir de coartada para inscribir, en el Registro Civil español, una filiación derivada de un tal convenio gestacional probibido expresamente en nuestro Derecho por el citado art. 10 LTRHA $y$, por ende, sin efecto jurídico alguno" 25 . En ausencia de una regulación legal expresa de estos contratos, a su juicio, la única solución procedente en estos casos era, cuando uno de los solicitantes fuera a su vez aportante de material genético, "la inscripción del menor con la determinación de la filiación del verdadero progenitor biológico, y como madre la mujer gestante, y posteriormente la adopción del hijo por la pareja matrimonial o de becho del progenitor biológico e inscrito". Añadía, además, que en caso de que ninguno de los padres intencionales fuera aportante de material reproductor, "el unico cauce legal procedente sería la institución jurídica de la adopción de los arts. 175 y ss. CC”.

Otros autores, sin embargo, han considerado insatisfactoria la postura del Tribunal Supremo, y han destacado que las vías alternativas que éste propone para dar cobertura jurídica al vínculo entre el menor y su familia intencional - aunque preferibles, sin duda, a la perpetuación de la situación de negación total del mismo-

jurídica" (p. 62), y afirma, además, que es imperiosa la necesidad de que el legislador actúe, "(p)orque exigir una doble determinación de la filiación del menor no debiera tranquilizar ni contentar a nadie” (p. 63).

${ }^{24} \mathrm{Ha}$ manifestado su posición favorable a la regulación de esta institución en varios artículos, entre ellos: VELA SÁNCHEZ, A. J. (2011) Propuesta de regulación del convenio de gestación por sustitución o de maternidad subrogada en España. El recurso a las madres de alquiler: a propósito de la Instrucción de la DGRN de 5 de octubre de 2010. Diario La Ley. 7621. VELA SÁNCHEZ, A. J. (2014). Soluciones prácticas para la eficacia en España de un convenio de gestación por encargo: de nuevo a propósito de la STS de 6 de febrero de 2014. Diario La Ley. 8309, 1. VELA SÁNCHEZ, A. J. (2017) Crimen en el bar. Regulemos ya en España el convenio de gestación por sustitución. Revista internacional de doctrina y jurisprudencia. 16.

${ }^{25}$ VELA SÁNCHEZ, J. A. (2013) El interés superior del menor como fundamento de la inscripción de la filiación derivada del convenio de gestación por encargo. Diario La Ley. 8162. p. 10. 
presentan inconvenientes significativos. En ambos casos existirá un periodo de incertidumbre jurídica respecto a la situación del menor, hasta tanto se logre llevar a término cualquiera de estas vías. Si durante ese tiempo de incertidumbre alguno de los padres falleciera, el menor quedaría en una situación de desprotección. Además, ambas "soluciones" dependen enteramente de la ulterior actuación de los padres comitentes; no existen cauces para obligarlos a reclamar la paternidad, ni a adoptar al menor, de manera que su eventual desinterés por seguir cualquiera de estas vías de reconocimiento de la filiación dejaría al menor desprotegido. En vista de estas debilidades, autores como CALVO CARAVACA y CARRASCOSA GONZÁLEZ ${ }^{6}$ consideran que el TS no hizo en su sentencia de 6 de febrero de 2014 una valoración adecuada del interés superior del menor, que aconsejaba el reconocimiento de la filiación acreditada en el extranjero, frente a esta doble filiación incierta. Junto a ello, se ha destacado también que este principio no debería presentarse como una fuerza contraria al orden público internacional. Al contrario, el principio del interés superior del menor es parte de nuestro orden público internacional, y ambos deben armonizarse y dirigir la interpretación del marco normativo vigente en un mismo sentido ${ }^{27}$. Ello se expresó también en el voto particular que acompañaba a la sentencia, que afirmaba que " $(E) l$ orden público en esta materia no debe valorarse desde la perspectiva de la contrariedad con la normativa interna, sino desde la consideración que merezca la tutela del interés del menor (...), cuya normativa reguladora tiene también características de orden público $y$ debe ser observada necesariamente por los jueces y tribunales en cuanto les afecte". Por otro lado, como también critica el voto particular, la excepción del orden público internacional ha de ser valorada de manera restrictiva, y siempre considerando las circunstancias concretas del caso, algo que no se hizo en la sentencia comentada ${ }^{28}$. Ello ha sido puesto de manifiesto, una vez más, por CALVO CARAVACA y CARRASCOSA GONZÁLEZ ${ }^{29}$, que han afirmado que para considerar vulnerado el orden público internacional español debería haberse comprobado la existencia de un perjuicio grave a la madre gestante o al menor: que los niños fueron objeto de comercio, que la madre

${ }^{26}$ CAlvo CARAVACA, A., CARRASCOSA GONZÁleZ, J. (2015) Op. cit. pp. 76 y ss.

27 Sobre la inclusión del interés del menor en el orden público se ha pronunciado Encarnación Roca: “(... pienso que en la noción de orden público está incluido el interés del menor, (...) (e)s decir, que la protección del interés del menor forma parte de los conceptos de orden público español, dado que España es parte en el Convenio Internacional de los Derechos del Niño, de 1989 (...). Por tanto y sin entrar a valorar si en la STS de 16 de febrero de 2014 y el ATS de 2 de febrero de 2015 se descuida o no dicha protección, lo que sí debe afirmarse es que inevitablemente la aplicación de este principio a estas situaciones debe llevar a una postura más activa que pasiva, tal como ha resultado de las sentencias del TEDH. En cualquier caso, los legisladores deben tenerlo en cuenta. En ROCA TRÍAS, E. (2015) Op. cit. p. 332.

${ }^{28}$ En parecido sentido, JIMÉNEZ BLANCO ha criticado la aplicación preventiva y apriorística de la excepción del orden público al caso analizado. En un artículo conjunto, esta autora y PRESNO LINERA realizan esta y otras críticas a la sentencia, desde los conceptos constitucionales de dignidad y libre desarrollo de la personalidad. PRESNO LINERA, M. A., JIMÉNEZ BLANCO, P. (2014). Libertad, igualdad ¿maternidad? La gestación por sustitución y su tratamiento en la jurisprudencia española y europea. Revista Española de Derecho Europeo. 51. pp. 1-24.

29 CALVO CARAVACA, A., CARRASCOSA GONZÁLEZ, J. (2015) Op. cit. p.78.

(C) UNED. Revista de Derecho Político

N. ${ }^{\circ} 107$, enero-abril 2020, págs 181-210 
gestante fue engañada, intimidada, víctima de violencia o que no quiso renunciar a su patria potestad sobre el menor, extremos todos ellos que no concurrían en el caso bajo examen. En parecido sentido, GONZÁLEZ MARTÍN ${ }^{30}$ ha afirmado que " $(C)$ ualquier visión absolutista de orden público se compadece mal con la función encomendada a los jueces y tribunales, que es la de resolver situaciones concretas. Seguramente, en muchas de ellas, los riesgos observados por el Tribunal Supremo — la cosificación del nacido o la denigración de la madre gestante — no concurran."

Personalmente, aun reconociendo la complejidad del conflicto de intereses que se plantea en estas situaciones, considero que la lectura más acertada del problema es la sostenida por quienes aconsejan evitar la situación de inseguridad jurídica que acompaña a la doble filiación, a través del reconocimiento de la filiación ya establecida en el extranjero, siempre y cuando se demuestre que la pareja comitente constituye un entorno familiar idóneo para el desarrollo del menor, y que no ha existido una situación extrema en la obtención del consentimiento de la mujer gestante. Lo contrario resultaría contrario al principio del interés superior del menor, en cuya virtud la "voluntad de castigo" a los padres intencionales no puede convertirse en un leiv motiv no confesado que oriente las resoluciones judiciales en un sentido desfavorable para los niños nacidos por gestación subrogada; por mucho que nuestro Derecho interno rechace esta figura, los menores implicados no fueron parte de estos contratos, y no debe pesar sobre ellos consecuencia perjudicial alguna en el disfrute de sus derechos.

\section{A MODO DE CONCLUSIÓN.}

Al margen de la posición que se defienda con relación a la oportunidad o no de convertir los acuerdos de gestación subrogada en contratos válidos para el Derecho interno, no hay duda de que, mientras perduren las diferencias legislativas entre distintos países en su tratamiento, continuarán existiendo casos de gestación subrogada internacional, que expondrán a los niños nacidos en el extranjero a situaciones de potencial desprotección de sus derechos. En el presente trabajo, se ha centrado la atención en los problemas que se suscitan a la hora de reconocer la filiación de estos menores en el Estado de residencia de sus padres intencionales, así como en la descripción del umbral mínimo de protección de los derechos de estos niños fijado por el TEDH en sus resoluciones más recientes a propósito de esta materia.

Como se ha visto, el Tribunal de Estrasburgo exige que una eventual negativa a admitir la validez de la gestación subrogada en el Derecho interno no se traduzca en la desprotección de los derechos de los niños y niñas involucrados. En concreto, ha establecido que una lectura del art. $8 \mathrm{CEDH}$ a la luz del principio del interés superior

${ }^{30}$ GONZÁLEZ MARTÍN, B. (2014). "No inscripción en el Registro Civil español de los menores nacidos mediante gestación por sustitución”. El notario del siglo XXI. 54, p. 4. 
del menor impone a los Estados parte la obligación de permitir el establecimiento de la filiación del menor nacido por gestación subrogada a favor del padre comitente, cuando este hubiera aportado su material genético para la fecundación. En cuanto al vínculo de filiación con la madre comitente que no aportó material genético, designada en el certificado de nacimiento legalmente establecido en el extranjero como "madre legítima", el Estado parte debe habilitar un medio para su reconocimiento o constitución, no siendo necesario que el medio elegido sea la inscripción en el registro nacional del certificado registral extranjero.

Así las cosas, si bien los Estados mantienen su libertad para elegir el cauce por el cual reconocerán o constituirán ex novo ese vínculo de filiación, el TEDH ha dejado claro que su establecimiento por una u otra vía viene impuesto por la obligación de respeto al derecho a la vida privada de los menores reconocido por el art. $8 \mathrm{CEDH}$. Esta exigencia, a mi juicio, ha de ser valorada de forma positiva, en la medida en que protege los intereses de los menores al tiempo que respeta la deferencia debida a los Estados parte, reconociéndoles un margen de decisión razonable en la elección de los medios con los que darán satisfacción a las obligaciones derivadas del CEDH. No obstante, como se ha comprobado en apartados anteriores, más que una solución definitiva a los problemas relacionados con la filiación de estos menores, la doctrina del TEDH puede considerarse un remedio incompleto, que logra sortear las consecuencias perjudiciales que más fácilmente podrían hacerse pesar sobre los menores, pero deja aún varios interrogantes sin respuesta y algunos flancos desprovistos de protección. Para corregir esta situación, y terminar con la inseguridad jurídica que afecta a los derechos de todas las partes implicadas, sería deseable atender las reiteradas llamadas que en los últimos años ha hecho la Conferencia de la Haya de Derecho Internacional Privado a la comunidad internacional, y adoptar un instrumento internacional vinculante sobre reconocimiento de decisiones judiciales extranjeras sobre filiación derivada de acuerdos de gestación subrogada internacional. Sin embargo, dadas las grandes divergencias de parecer de los Estados respecto a esta figura, y las reticencias que aún despierta la idea de facilitar el establecimiento de la filiación entre los menores nacidos y sus padres intencionales, no es probable que un instrumento de estas características suscite el consenso necesario en un futuro próximo. En este sentido, es destacable que el Comité de Bioética de España, en su último informe a propósito de los aspectos éticos y jurídicos de la maternidad subrogada, concluía que cualquier reforma legislativa en esta materia debería mantener el rechazo a esta figura, y "orientarse a lograr que la nulidad de esos contratos sea también aplicable a aquellos celebrados en el extranjero", y no, por tanto, a la facilitación de este trámite. No obstante, reconocía igualmente que en el periodo de transición que necesariamente habrá de mediar entre el momento presente y la consecución del objetivo último declarado por los expertos _- "una probibición universal de la maternidad subrogada internacional"-, 
debe continuar garantizándose que la filiación de estos niños "se realice conforme a la doctrina establecida por el TS"31.

La posición del Comité de Bioética, en un precario equilibrio entre el deseo de desincentivar el fraude de ley cometido por quienes realizan más allá de las fronteras nacionales un contrato cuya validez es rechazada por el Derecho interno, y la preocupación por la situación de los menores implicados, evidencia la complejidad de la situación analizada. De un lado, es lógico exigir el respeto a la legislación interna que, en último término, busca proteger a las mujeres gestantes y a los menores de posibles abusos. De otro lado, sin embargo, no puede desconocerse que, ante el hecho consumado del nacimiento de un menor, el Estado tiene el deber de salvaguardar sus intereses. No es sencillo encontrar soluciones que garanticen adecuadamente los derechos de todas las partes implicadas, pero, personalmente, considero que dificultar el esclarecimiento de la filiación en estos casos es una respuesta extemporánea y desaconsejable, en la medida en que los mayores perjuicios derivados de la misma pesarán sobre el culpable equivocado: un menor que nada tuvo que decir sobre las circunstancias en que fue concebido. Obstaculizar el disfrute de sus derechos, independientemente del efecto desincentivador o no que pudiera tener en las decisiones de terceras personas que se planteen acudir a la gestación subrogada en el extranjero, provoca un perjuicio cierto en la vida de un niño que ni siquiera podría haber sido parte del acuerdo de subrogación que se pretende erradicar y, a mi juicio, contraviene las exigencias de ponderación de intereses derivadas del respeto al principio del interés superior del menor.

\section{BIBLIOGRAFÍA}

Balaguer Callejón, M. L. (2017). Hij@s del mercado. La maternidad subrogada en un Estado social. Cátedra.

BERTI Di MARINIS, G. (2015) "Maternità surrogata e tutela dell'interesse superiore del minore: una critica alla luce di un recente intervento della Corte EDU”. Actualidad Jurídica Iberoamericana, 3, pp. 287-312.

Blanco-Morales Limones, P. (2015). "Una filiación: tres modalidades de establecimiento. La tensión entre la ley, la biología y el afecto”. Bitácora Millennium dipr: Derecho Internacional Privado, $1,1$.

Calvo Caravaca, A., Carrascosa González, J. (2015) "Gestación por sustitución y derecho internacional privado. Más allá del tribunal supremo y del tribunal europeo de derechos humanos". Cuadernos de Derecho Transnacional., 7, 2, pp. $45-113$.

31 COMITÉ DE BIOÉTICA DE ESPAÑA. (2017). Informe del Comité de Bioética de España sobre los aspectos éticos y jurídicos de la maternidad subrogada. pp. 91-92. Informe completo disponible en: http://assets.comitedebioetica.es/files/documentacion/es/informe_comite_bioetica_aspectos_eticos_juridicos_maternidad_subrogada.pdf (consultado el 23/10/2019). 
Calvo Caravaca, A., Carrascosa González, J. (2016) Derecho Internacional Privado. Volumen II. Decimosexta Edición. Comares. pp. 386-407.

Durán Ayago, A. (2014). "Sentencia del Tribunal Supremo, Sala de lo Civil Pleno, 835/2013, de 6 de febrero de 2014 (ROJ STS 247/2014): Gestación por sustitución: problemas en la determinación de la filiación en España”. Ars Iuris Salmanticensis. 2, 2, pp. 277-279.

Durán Ayago, A. (2014) "Sentencias del Tribunal Europeo de Derechos Humanos, caso Mennesson c. France $\left(n .^{\circ}\right.$ 65192/11) y caso Labassee c. France (n. ${ }^{\circ}$ 65941/11), de 26 de junio de 2014". Ars Iuris Salmanticensis. 2, pp. 280-282.

Durán Ayago, A. (2012). "El acceso al Registro Civil de certificaciones registrales extranjeras a la luz de la Ley 20/2011: relevancia para los casos de filiación habida a través de gestación por sustitución”. Anuario español de derecho internacional privado, 12, pp. 265-308.

FARnós Amorós, E. (2010) "Inscripció a Espanya de la filiació derivada de l'accés a la maternitat subrogada a California”. Indret: Revista para el Análisis del Derecho. 1

Feraci, O. (2015) "Maternità surrogata conclusa all'estero e Convenzione europea dei diritti dell'uomo: riflessioni a margine della sentenza Paradiso e Campanelli c. Italia". Cuadernos de derecho transnacional. 7, 2, pp. 420-439.

Heredia Cervantes, I. (2014). "El Tribunal Supremo y la gestación por sustitución: crónica de un desencuentro”. El notario del siglo XXI. Disponible en: http:// www.elnotario.es/hemeroteca/revista-54/3716-el-tribunal-supremo-y-la-gestacion-por-sustitucion-cronica-de-un-desencuentro (Consultado el 17/06/2019)

LAMm, E. (2012) "La importancia de la voluntad procreacional en la nueva categoría de filiación derivada de las técnicas de reproducción asistida". Revista de bioética $y$ derecho. 24, pp. 76-91.

LAMM, E. (2013) Gestación por sustitución: ni maternidad subrogada ni alquiler de vientres. Publicacions i Edicions de la Universitat de Barcelona. Barcelona.

Marrades Puig, A. (2017). El debate sobre la gestación subrogada en España: entre el deseo, la dignidad y los derechos. Revista Europea de Derechos Fundamentales. 30, pp. 153-177.

Presno Linera, M. A., Jiménez Blanco, P. (2014). Libertad, igualdad ¿maternidad? La gestación por sustitución y su tratamiento en la jurisprudencia española y europea. Revista Española de Derecho Europeo. 51. pp. 1-24.

QuiÑones Escámez, A. (2009). "Doble filiación paterna de gemelos nacidos en el extranjero mediante maternidad subrogada: en torno a la RDGRN de 18 de febrero de 2009”. Indret: Revista para el Análisis del Derecho. 3.

Roca Trías, E. (2015). "Dura Lex Sed Lex. O de cómo integrar el interés del menor y la prohibición de la maternidad subrogada.", en Benavente Moreda, P. y FARNÓs AMORós, E. (Coords.). Treinta años de reproducción asistida en España: una mirada interdisciplinaria a un fenómeno global y actual. Boletín del Ministerio de Justicia. pp. 301-338.

(C) UNED. Revista de Derecho Politico

205

N. 107 , enero-abril 2020, págs 181-210 
Salazar Benítez, O. (2017). La gestación por sustitución desde una perspectiva jurídica: Algunas reflexiones sobre el conflicto entre deseos y derechos. Revista de Derecho Político. 99, pp. 79-120.

Shenfield, F., De Mouzon, J., Pennings, G., Ferraretti, A. P., Nyboe AnDersen, A., De Wert, G., ... \& Eshre "Taskforce on Cross Border Reproductive Care. (2010). Cross border reproductive care in six European countries". Human Reproduction, 25, 6, 1361-1368.

VAquero Pinto, M. J. (2018) “¿Debe admitirse y regularse la gestación por sustitución?”, en Barber Cárcamo, R., Quicios Molina, M.s., Vereda Server, R.A. (Coords.) Retos actuales de la filiación. Tecnos. pp. 229-268.

Vela SÁnchez, A. J. (2017) Crimen en el bar. Regulemos ya en España el convenio de gestación por sustitución. Revista internacional de doctrina y jurisprudencia. 16.

Vela SÁnchez, A. J. (2017) ¿Ha variado el TEDH su Doctrina favorable a los convenios de gestación por sustitución realizados en países que legalmente los permiten? A propósito de la Sentencia de la Gran Sala del TEDH de 24 de enero de 2017. Diario La Ley. 8953, 1.

Vela SÁnchez, A. J. (2014). Soluciones prácticas para la eficacia en España de un convenio de gestación por encargo: de nuevo a propósito de la STS de 6 de febrero de 2014. Diario La Ley. 8309, 1.

Vela Sánchez, A. J. (2013) El interés superior del menor como fundamento de la inscripción de la filiación derivada del convenio de gestación por encargo. Diario La Ley. 8162.

Vela Sánchez, A. J. (2011) Propuesta de regulación del convenio de gestación por sustitución o de maternidad subrogada en España. El recurso a las madres de alquiler: a propósito de la Instrucción de la DGRN de 5 de octubre de 2010. Diario La Ley. 7621.

Title:

International surrogacy arrangements and best interests of the child: Jurisprudence of the ECHR and Spanish authorities' response.

\section{Summary:}

I. Approach to the problem and main purpose of this paper. II. Children's right to respect for their private life when there is a biological tie with their commissioning father: 
Cases of Mennesson and Labassée v. France and Advisory Opinion requested by the French Court of Cassation. (Request no. P16-2018-001). III. Minor's vulnerability in case of lack of biological tie between him and the commissioning parents: Case of Paradiso and Campanelli v. Italy.

IV. Considerations on ECHR jurisprudence: States Parties' obligations and questions that remain unsettled. V. Spanish authorities' response to international surrogacy arrangements in the light of ECHR's jurisprudence. VI. Final thoughts on the matter.

\section{Resumen:}

Las diferencias en el tratamiento legislativo que los Estados dan a la gestación subrogada dan lugar a desplazamientos de personas residentes en países donde esta figura está prohibida, o carece de regulación, hasta países en los que este tipo de contratos están permitidos. Precisar la filiación de los menores nacidos como fruto de estos acuerdos en el Estado de residencia de sus padres intencionales plantea problemas jurídicos de extraordinaria complejidad, y las respuestas de los ordenamientos internos y los tribunales nacionales a esta situación pueden poner en riesgo los derechos de respeto a la vida privada y familiar de estos niños. Ello ha motivado diferentes pronunciamientos del Tribunal Europeo de Derechos Humanos que, si bien ha entendido que la eventual legalización de la gestación por sustitución es una cuestión que corresponde decidir libremente a los Estados, exige que su negativa a admitir la validez de estos contratos no se traduzca en la desprotección de los menores involucrados. Desde que dictara sentencia en los casos Mennesson y Labassée c. Francia en 2014, quedó establecido que negar toda posibilidad de reconocimiento de un lazo paternofilial entre un niño nacido por gestación subrogada y su padre intencional, cuando éste hubiera aportado su material genético, sería contrario al derecho del menor al respeto de su vida privada, que requiere que toda persona pueda establecer su identidad. En caso de no existir vínculo genético alguno entre el niño y los padres intencionales, su jurisprudencia no nos permite aún extraer una respuesta clara acerca de los límites de la actuación estatal.

En lo que se refiere a los casos en los que el padre comitente sea, además, padre biológico del niño, la reciente publicación del Dictamen de 10 de abril de 2019 ha resuelto algunas incógnitas que quedaron abiertas tras los pronunciamientos anteriormente citados: en virtud del art. $8 \mathrm{CEDH}$, sobre los Estados parte no solamente pesa la obligación de permitir el establecimiento de la filiación del menor a favor de su padre biológico, sino también el deber de permitir que se reconozca o constituya ex novo un vínculo jurídico a favor de la madre comitente. El respeto al Convenio exige dar cobertura jurídica a este vínculo maternofilial, pero no impone un medio determinado para ello, siendo suficiente que el medio elegido sea eficaz y no dilate la situación de inseguridad jurídica en el tiempo. De este modo, cabe que el Estado reconozca la filiación que consta en una decisión 
extranjera, o que permita su constitución por otras vías, como la adopción; ambas alternativas darían cumplimiento a las exigencias del CEDH. Es preciso señalar, no obstante, que no todos los medios a disposición de los Estados dan un mismo grado de satisfacción a los derechos en juego. En este sentido, la respuesta que actualmente dan las autoridades españolas a este tipo de situaciones, a pesar de cumplir el estándar mínimo de protección fijado por el Tribunal de Estrasburgo, no parece una solución idónea para la mayor satisfacción de los intereses de los menores.

\begin{abstract}
:
Due to the differences on the legal treatment that States give to gestational surrogacy, some couples travel from countries where these arrangements are forbidden to places where they are allowed. Determining the parentage of the child born as a result of these contracts raises some legal issues that are not easy to solve. In this scenario, minor's rights may be at risk. It has led the European Court of Human Rights to determine that the State Parties are free not to legalize gestational surrogacy, but this decision cannot lead to leaving the minors unprotected. According to the Court (cases Mennesson and Labassée), denying every possibility of recognition of a parent-child relationship with the intended father, when he is the biological father, would entail a violation of the child's right to respect for his private life. When it comes to recognising a parent-child relationship in cases where there is not a biological link between the born child and any of the intended parents, the Court's jurisprudence does not give us a clear response on the State Parties' obligations so far.

In the advisory opinion delivered recently (10 April 2019), in response to the request made by the French Court of Cassation, the ECHR has given an answer to some of the questions that remained unsettled. When a child is born abroad through a gestational surrogacy arrangement and was conceived using the gametes of the intended father and a third-party donor, the child's right to respect for private life requires the State not only to recognise that link, but to provide a possibility of recognition of a legal parent-child relationship with the intended mother too. Such recognition may take the form of entry in the national register of births of the details of the birth certificate legally established abroad, but it may as well take another one. The State Parties are free to use other means, such as adoption of the child, as long as the procedure laid down by domestic law could be implemented promptly and effectively. However, not every mean would serve the child's interest with a comparable degree of satisfaction. Spanish authorities' response to these situations, for example, does not seem to be the optimal solution when it comes to covering the needs of the children.
\end{abstract}


Palabras clave:

gestación subrogada, interés superior del menor, vida privada, vida familiar, TEDH.

Key words:

Gestational surrogacy, best interests of the child, private life, family life, ECHR 
